\title{
Professional Development of Bachelor Designers by Means of Information and Communication Technologies
}

\author{
Lyajsan H. Kadyjrova, Elmira G. Akhmetshina, Liliya R. Zaripova, Igor A. Peremislov
}

\begin{abstract}
A developed information community assumes a broad and active use of information and communication technologies (ICT) in the education system, which is due to a number of factors that accompany the process of social development. One of the first to highlight is the introduction of information and communication technologies in education in order to accelerate the transfer of knowledge and experience accumulated by mankind from generation to generation, and from person to person. The second factor to be called is the possibility of improving the quality of education in the process of mastering information and communication technologies, which allows a person to more successfully adapt to what is happening around, i.e. to social changes. The third factor is the active and fairly effective implementation of information and communication technologies in the education system, which is a guarantee of updating the education system in accordance with the needs of modern society. This paper discusses the use of information and communication technologies in the preparation of future bachelors-designers as one of the organizational forms of innovative type teaching at a university, based on modern achievements of the psychological and pedagogical sciences, educational materials of a new generation and widespread use of electronic educational resources. The variety of diverse actions performed by a designer requires their systematization by means of information and communication technologies and bringing them into line with the competencies mastered in the learning process. Through the introduction of computer technologies in the design education system and mastering ArchiCad and Artlantis Render programs by a student going improvement of his/her professional skills as future experts in the field of design, and accordingly, increasing their competitiveness in the labour market. At the same time, the process of forming the creative activity of future designers requires, first of all, the development of their spatial and design thinking; therefore, when teaching a teacher, it is necessary to make the process of mastering information and communication technologies proportionate to the process of developing student's intellectual characteristics.

Key words: information and communication technologies, bachelor-designer, graphic design, art and design competence.
\end{abstract}

\section{INTRODUCTION}

The relevance of our research is due to the need of modern education for the formation and acquisition by bachelors-designers of the skills concerning competent use of information and communication technologies in future professional activities.

Revised Manuscript Received on November 08, 2019.

* Correspondence Author

Lyajsan H. Kadyjrova, Kazan Federal University

Elmira G. Akhmetshina, Kazan Federal University

Liliya R. Zaripova, Kazan Federal University

Igor A. Peremislov, Argosy University, Business and Management School
In actual practical work, the designer performs complex and diverse actions. They can conditionally be divided into several groups: ergonomic, research, constructive, design, economic, organizational. All these groups require systematization to prepare future designers to solve the above problems by means of information and communication technologies.

The study of scientific works in the field under consideration helped to reveal the fact that the issues of professional development of bachelors-designers by means of information and communication technologies have not been sufficiently studied. The analysis showed that almost all authors agree that the study of information and communication technologies is one of the main competencies in the training of bachelor-designers.

\section{METHODS}

One of the important student learning aspects is the formation of art and design competence of future specialists in the context of the educational paradigm of modern design [1]. Informatisation of society leads to a change in the traditional forms and values of project culture. The practical implementation of the planned, which is expressed as a technique or its language, a reflection of creative consciousness and will, is conceptual. The enrichment of the plastic language of the expression of the concept is due to the processes of informatisation that transform it. As an example, we could use media technologies in professional activities, such as two- and three-dimensional graphics for designing an environment

Information and communication technologies can be an effective means of activating innovative components in the work of a designer, and participate in the creation of new ideas and artistic images. For the development of professional skills and the worldview formation of future designers, it is necessary to create unusual and intricate design situations in which students are invited to "live" them while remaining in the creative work [2].

The specificity of information and communication technologies lies in that it is, first of all, a certain amount of information synthesizing a space. The parameters of an on-screen computer image are not only the height, width, depth, colour, and contrast, but also the motion parameters, the dynamics of the interaction between the user and the program, the simultaneity of several information blocks [3]. The principles of design education reveal the need to transfer the professional qualities of a future specialist to a wider level. He should be characterized by the formation of a new reality in 
different fields of knowledge, possession of the project type of thinking and the ability to overcome communication boundaries.

Mastering by a student-designer of computer technologies and graphic software packages modernizes his/her design skills, for example, concerning volumetric interior design with the aim of further processing an art form and demonstrating the design results to his/her customer. To optimize the formation of creative activity of a future specialist in the field of design, his/her spatial and design thinking, the emphasis in training should be placed on the development of their intellectual characteristics.

The use of graphic programs plays an important role in the organization of the educational process, since they are of particular interest to students. This, in turn, contributes to the formation of important professional qualities, such as intuition, imaginative thinking, and professional thinking.

Graphic editors are programs that support the process of creating and subsequent processing of images on a computer. They are divided into two categories: raster and vector. Raster editors provide the highest accuracy of gradation of colours and halftones. A raster image is stored using dots, each of which has a specific colour (pixels). The most popular bitmap graphics editor is Adobe Photoshop. To obtain pixel information, an image is rasterized and the plane is divided into elements of the same shape which are called raster's. Further, the colour characteristic of a raster is averaged and becomes a pixel, i.e. an element of a pixel image. It follows that the numerous pixels, when connected, create a bitmap image. Among the advantages of a raster image, one can single out the ability to achieve high realism of an image. Among the shortcomings is a decrease in quality when increasing the image; large file size; the need for a long period of time for processing complex images.

To successfully study and master the features of raster graphics, we can use the following tasks: editing photos; creating a new picture from a finished image; montages on various topics; creation of images by free drawing. These exercises will prepare bachelors-designers for solving highly specialized problems and master the basic technologies for working with raster images.

When completing a photo editing task, the technology of retouching and restoring damaged photos is mastered. It is very important here that various technological methods were used to complete the task, for example, the functions of masking, retouching, editing, adjusting colour and brightness balance, working with layers and scaling. These tasks are a good preparation for students to study such disciplines as "Form making" and "Design", and also to carry out research work. An electronic library with a variety of textures, photographs of various objects of the surrounding world will allow a student to more successfully master a course in computer technology.

Vector images are composed of such objects as a point, line, circle; they are stored in computer memory as graphic primitives. Unlike a raster image, a vector is based on mathematical formulas, thereby representing their graphic expression. Advantages are minimum file size; image is not distorted when zoomed. Among the shortcomings are the following: limitation in the depicted object; difficulty in converting from raster graphics to vector. CorelDraw and Adobe Illustrator are usually used for work with vector images.
One of the special types of graphics programs is three-dimensional graphics. It has been widely used in architectural modelling, in the industry of computer games, in the design of television channels, and in advertising.

In ArchiCAD software package, the design process is not limited to drafting. The process of creating an interior in the framework of computer modelling is the construction of a virtual model, the design of drawings, and the preparation of a set of project documentation. At the same time, the final result of the design project development is the transfer to customers or specialists of related professions in the field of architecture and construction of project documentation, which is prepared and presented in electronic form or in the form of paper copies, that is, ordinary drawings and texts.

To create visual material in relation to the created virtual model of the project paired with the ArchiCad program, the Artlantis Render program is used. This computer program is used to set light sources, fill the spaces of the future interior with light, and apply textures to objects, items and a virtual model of the interior itself.

Artlantis Render is a set of tools for creating photographic-quality images based on the 3D model of various modelling programs: ArchiCAD, AutoCAD, etc. At the same time, the program provides convenient and intuitive tools for changing textures, editing its properties, working with colour and light sources. As a result, a designer can build high-quality photo, video and presentation materials in the shortest possible time.

Mastering by a student-designer of computer technologies and graphic software packages modernizes his/her skills in designing a three-dimensional interior with the aim of further processing the art form and demonstrating the results of design to a customer. Thus, it is through the introduction of computer technology in the system of design education and the mastering by a student of the program package ArchiCad and Artlantis Render that the professional skills of future specialists in the field of design are improved, and their competitiveness in the labour market increases accordingly. The list of programs developed specifically for designers is increasing every year.

In the multistage system of Russian education, the process of introducing and developing the skills of a competent use of information and communication technologies is consistent and continuous. It begins at the pre-university level, thus being the basis for further education at the university, and continuing it in postgraduate studies. During training at a university, each student must go through the stage of formation of their general information and communication technology competencies, and also through the mandatory stage of formation at a professional level, after which the student must demonstrate certain skills in the use of information and communication technologies:

- Search for information in various sources, resources (books, magazines, electronic media, and search engines) and the ability to critically interpret it;

- The choice of methods for studying professional information and literature, taking into account their own capabilities and capabilities of modern computer technologies;

- Development, modification, preparation of graphic information of various kinds with the help of information and communication technology programs; 
- Participation in the modelling and design of the information environment for solving professional problems by means of information and communication technologies [4; 5].

\section{RESULTS AND DISCUSSION}

Information and communication technologies directly affect the formation of the design culture of future designers, namely:

- affect the users' perception, taking into account their emotional sphere, the synthesis of visual, auditory and motor images in a joint object of communication [6];

- provide users with an opportunity to create illusions of three-dimensional objects of the real world, illusions of movement, imitation of almost any visual means of expression, as well as demonstrate them;

- information and communication technologies can help develop models of self-developing information systems. Their simplest form is the system of interactive bulletin boards, electronic conferences; their content is developed due to the ability of users to freely post information. For example, these are many art projects on the Internet, and joint Internet works;

- through the use of computer technology, a user has the ability to master the necessary information with his/her own speed, motivation and direction of thought;

- information and communication technologies are characterized by a visual nature, which is characterized by a certain range of capabilities that contribute to increasing the visibility and visual perception of a user [7].

Fig. 1 shows the degree of mastering of information and communication technologies in solving professional problems by students of control (CG) and experimental (EG) groups before students study the developed course by EG. The data are presented based on the results of the final creative assignment and the test in the standings. From Fig. 1, we can conclude that the skill level in mastering of information and communication technologies in both groups is approximately the same. In the CG, $16.7 \%$ of students were able to complete the assignment "excellently", and in the EG $18.2 \%$, "good" in the CG - 25\%, and in the EG - $27.3 \%$, and "satisfactory" in the CG - 58, $3 \%$, in the EG $-54.5 \%$.

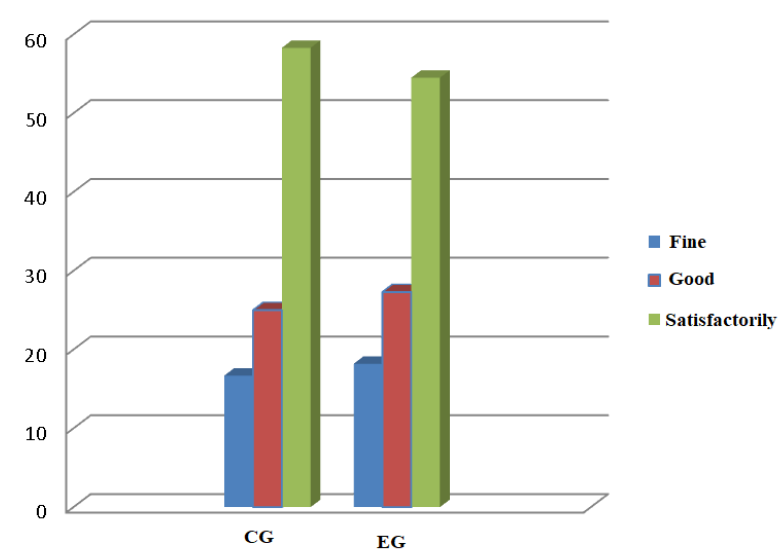

Pic 1. The ICT mastering level by students from the $C G$ and the EG before studying the discipline (\%)

To determine the level of perception by students' of the material learnt on the course "Computer Modelling for Designers", a creative task and a final test were set.

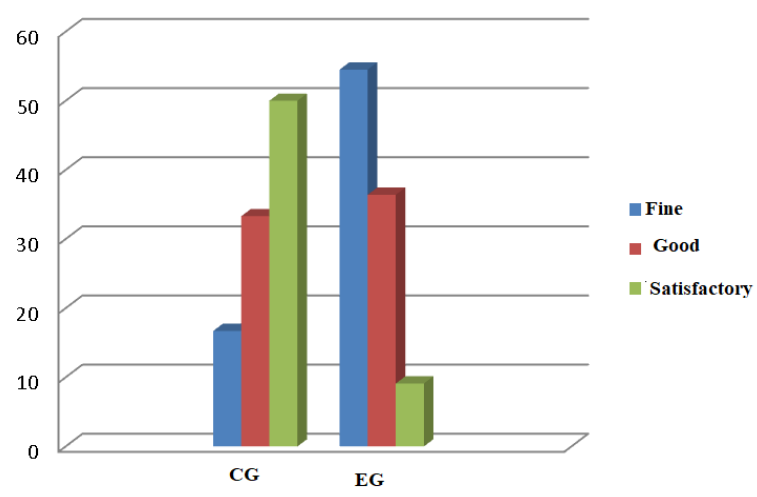

Pic 2. The level of ICT mastering by students of the CG and the EG according to the results of the study (\%)

Fig. 2 shows the information and communication technologies mastering degree by CG and the EG students based on the results of a creative assignment and the final test conducted after studying the discipline in the EG. It should be noted that the performance of the experimental group has improved significantly. The percentage of students who know information and communication technologies "excellent" and "good" has increased, now they are 54.5\% and 36.4\%, respectively. The percentage of students who know the discipline "satisfactorily" significantly decreased from $54.5 \%$ to $9.09 \%$.

\section{SUMMARY}

The integration of information and communication technologies in the educational process provides preparation of bachelors-designers to solve professional problems by means of information and communication technologies. It is important to introduce them into intersubject communications with the information orientation, as well as with general professional, economic, and professional disciplines, with practice, courseworks, and final qualification works [8-12-13-14].

The introduction of information and communication technologies in the educational process is an important reform in education over the past few years. The development of new technologies and the constant updating of information help higher educational institutions to develop in accordance with modern trends in education [9-15]. The creative diversity of a designer implies a creative and extraordinary approach to the preparation of future bachelor-designers. A teacher, together with each student, using the information and communication technologies have an opportunity to compose a personal educational process with the choice of the most appropriate forms, modules, methods for more effective teaching.

Working with laptops together with interactive equipment allows implementation of e-learning of future designers. Students get a sense of real professional activity through the use of information and communication technologies. A production designer designs and models the future product directly on a computer. The information and communication technologies automate routine operations, developing the flexibility of thinking, thereby forming creative thinking [10; $11]$. 


\section{CONCLUSION}

The results of the study showed that the degree of preparedness of bachelors-designers for solving professional problems by means of information and communication technologies before and after the experiment in both groups differ from each other, but in the EG the differences are more significant.

We can say that a change in the degree of preparedness of bachelor-designers in solving professional problems by means of information and communication technologies was formed under the influence of the experiment. The most effective indicators of the model are indicators that the number of students with a critical level has decreased in favour of increasing the overall percentage of students with a high level in the experimental group.

In the process of monitoring the educational and cognitive activities of students, it was revealed that students have significantly increased interest in using information and communication technologies when solving professional problems, as well as the level of self-control and self-esteem has changed. Many of them have learned to understand the specifications of the designer professional activity and to apply information and communication technologies in solving professional tasks.

\section{ACKNOWLEDGEMENTS}

The work is performed according to the Russian Government Program of Competitive Growth of Kazan Federal University.

\section{REFERENCES}

1. Galeeva Zukhra N., Yao Michail K., Emanova Juliana G. Project thinking as the basis of professional competence of the designer // Amazonia Investiga. - 2018.- Vol. 7, Is.15. - P.133-138

2. Klara K. Karamova, Irina M. Mayorova, Gulnaz H. Myhtarova, Rezeda.A Fakhrutdinova, Adnan M. Hakki. Development of creative activity of students-designers method of metaphorical associative cards (MAC)" "Amazonia oS" http://www.udla.edu.co/revistas/index.php/amazonia-investiga/article /view/947 p. $279-286$

3. Grigoriev, S.G. Possibilities of using information and communication technologies in open education [Electronic resource] / S.G. Grigoriev, V.V. Grinshkun URL.: http://www.ido.rudn.ru/Open/ikt/3.htm (accessed date: 8.01.2013)

4. Makarova T.V. The structure and content of information and communication technologies, the competence of engineers of the specialty "Information technology in design" / T.V. Makarova // Omsk Scientific Herald. - 2007. - No. 2 (56). - P. 175-178

5. Koroleva L.Y., Khayrullina E.R. The role of information technology in the development of creativity of a future designer // Fundamental Research. - 2014. - No. 9. - P. 658-662

6. Fomin, A.P. Pedagogical consciousness in the conditions of virtualization of social reality // A.P. Fomin. Abstract of a thesis for the degree of the Doctor of Philosophy. 2009. -38 p.

7. Brown, A. Technology-enhanced learning: strengthening links with practitioners / A. Brown, J. Bimrose // Book of abstracts 12-th International conference on technology supported learning and training. Berlin, 2006. - P.36

8. E-Learning: Erfolgsfaktoren und Einsatzkonzepte mit interaktiven Medien / ed.U. Dittler.Muenchen; Wien: Oldenbourg Verl., 2002. - P. 318

9. Kayumova G.F., Makarova V.F., Galiullin R.R and Khaziev R.I., Yuldybaeva G.V. and Abdrafikova G.Kh. Moral education of high school students in national (Turkic) schools through literature. International Journal of Mechanical Engineering and Technology (IJMET) Volume 9, Issue 10, October 2018, pp. 1467-1475

10. Janet Hanson Displaced but not replaced: the impact of e-learning on academic identities in higher education / Janet Hanson // Teaching in Higher Education.-2009. Vol. 14, № 5. - P.553-564
11. Mohr, A. T. Learning style preferences and the perceived usefulness of e-learning / A. T. Mohr, D. Holtbriigge, N. Berg. // Teaching in Higher Education. 2012. - Vol. 17, № 3. - P.309-322

12. Ameen, A. M., Ahmed, M. F., \& Hafez, M. A. A. The Impact of Management Accounting and How It Can Be Implemented into the Organizational Culture. Dutch Journal of Finance and Management, 2(1), (2018).02.

13. Carreto, C., Gêgo, D., \& Figueiredo, L. An Eye-gaze Tracking System for Teleoperation of a Mobile Robot. Journal of Information Systems Engineering \& Management, 3(2), (2018). 16.

14. Peranginangin, S. A., Saragih, S., \& Siagian, P. Development of Learning Materials through PBL with Karo Culture Context to Improve Students' Problem Solving Ability and Self-Efficacy. International Electronic Journal of Mathematics Education, 14(2), (2019). 265-274 https://doi.org/10.29333/iejme/5713

15. Kondubaeva, M. R., Bekalay, N. K., Aubakirova, A. K., Ongarbaeva, A. T., \& Tolkinbayev, A. K. The problem of correctness and reliability of the study in trilingual education. Opción, 34(85-2), (2018). 517-543. 